This is an author produced version of a paper published in Journal of Nuclear Materials.

This paper has been peer-reviewed but may not include the final publisher proof-corrections or pagination.

Citation for the published paper:

Tereza Pavelkova, Vaclav Cuba, Eva de Visser-Týnova, Christian Ekberg, Ingmar Persson. (2016) Preparation of UO2, ThO2 and (Th,U)O2 pellets from photochemicallypreparednano-powders. Journal of Nuclear Materials. Volume: 469, pp 57-61.

http://dx.doi.org/10.1016/j.jnucmat.2015.11.041.

Access to the published version may require journal subscription.

Published with permission from: Elsevier.

Standard set statement from the publisher:

(C) Elsevier, 2016 This manuscript version is made available under the CC-BY-NC-ND 4.0 license http://creativecommons.org/licenses/by-nc-nd/4.0/

Epsilon Open Archive http://epsilon.slu.se 


\title{
Preparation of $\mathrm{UO}_{2}, \mathrm{ThO}_{2}$ and $(\mathrm{Th}, \mathrm{U}) \mathrm{O}_{2}$ pellets from photochemically-prepared nano- powders
}

Tereza Pavelkováa, Václav Čuba ${ }^{\mathrm{a}}$, Eva de Visser - Týnováb ${ }^{\text {, Christian Ekberg }}{ }^{\mathrm{c}}$, Ingmar Persson $^{\mathrm{d}}$

a Czech Technical University in Prague, Faculty of Nuclear Sciences and Physical Engineering, Břehová 7, Praha 1, 11519 Czech Republic

b Nuclear Research and consultancy Group (NRG), Research \& Innovation, Westerduinweg 3, 1755 LE Petten, The Netherlands

c Nuclear Chemistry/Industrial Materials Recycling, Chalmers University of Technology, SE-41296 Göteborg, Sweden

d Department of Chemistry and Biotechnology, Swedish University of Agricultural Sciences, P.O.Box 7015, SE-750 07 Uppsala, Sweden

\begin{abstract}
Photochemically-induced preparation of nano-powders of uranium and/or thorium oxides and their subsequent pelletizing has been investigated. The preparative method is based on the photochemically induced formation of solid precursors in aqueous solution containing uranyl and/or thorium nitrate and ammonium formate. The EXAFS analyses of the precursors show that the irradiation of thorium containing solutions yields solid $\mathrm{ThO}_{2}$ with low structural order, and the irradiation of uranium containing solutions yields the mixture of U(IV) and U(VI) compounds. The U-containing precursors were carbon free, thus allowing direct heat treatment in reducing atmosphere without pre-treatment in the air. Subsequent heat treatment at 300-550 ${ }^{\circ} \mathrm{C}$ yields nano-crystalline $\mathrm{UO}_{2}$, $\mathrm{ThO}_{2}$ or solid ( $\left.\mathrm{Th}, \mathrm{U}\right) \mathrm{O}_{2}$ solutions with high purity, welldeveloped crystals, and nanoparticles with diameter $<15 \mathrm{~nm}$. The prepared nano-powders of oxides were pelletized without any binder (pressure $500 \mathrm{MPa}$ ), the green pellets were subsequently sintered at $1300{ }^{\circ} \mathrm{C}$ under an $\mathrm{Ar}: \mathrm{H}_{2}$ (20:1) mixture $\left(\mathrm{UO}_{2}\right.$ and (Th, $\mathrm{U}_{2} \mathrm{O}_{2}$ pellets) or at $1600{ }^{\circ} \mathrm{C}$ in ambient air $\left(\mathrm{ThO}_{2}\right.$ pellets). The theoretical density of the sintered pellets varies from 91 to $97 \%$.
\end{abstract}

Keywords: nanoparticles, uranium(IV) oxide, thorium oxide, UV radiation, EXAFS, pelletizing 


\section{Introduction}

Uranium (IV) oxide $\left(\mathrm{UO}_{2}\right)$, thorium (IV) oxide $\left(\mathrm{ThO}_{2}\right)$ and their mixed oxides $\left((\mathrm{Th}, \mathrm{U}) \mathrm{O}_{2}\right)$ have been widely utilized and tested as nuclear fuels in various types of reactors [1,2]. Prepared oxide powders are typically mixed with binders and lubricants and then compacted into the pellets by a powder metallurgy method. $\mathrm{UO}_{2}$ and $\mathrm{ThO}_{2}$ powders are typically compacted at 150-500 and 40-300 MPa [3,4], respectively. The density of the green (i.e. non-sintered) pellets usually reaches 50-60\% of theoretical density (TD) [3]. Green pellets are subsequently sintered where the first step is dewaxing (removal of volatile additives at approximately $500-800{ }^{\circ} \mathrm{C}$ ) [3]. $\mathrm{UO}_{2}$ pellets are then sintered at temperatures of $1600-1800{ }^{\circ} \mathrm{C}$ under controlled (reducing) atmosphere for 3-10 hours [3], whereas $\mathrm{ThO}_{2}$ pellets are sintered at temperatures of 1600-1700 ${ }^{\circ} \mathrm{C}$ and the sintering can be performed under both oxidizing and reducing conditions [4]. Generally, sintered pellets are distinguished by high mechanical strength and density [3]; the density achieved in laboratory conditions is usually higher than $80 \%$ TD [5]; pellets with $95 \%$ TD are denoted as high density pellets [6].

$\mathrm{UO}_{2}$ and $\mathrm{ThO}_{2}$ powders are typically prepared via precipitation or sol-gel routes [4]. Novel preparations of various oxides via the photochemical method have recently also been reported [7] (the mechanisms of water photolysis and oxides formation are summarized therein). The biggest advantage of this method is formation of nanoparticles with uniform particle size. The material preparation is based on the irradiation of aqueous solutions of metal salts and $\mathrm{OH}$ radical scavengers, resulting in the formation of finely dispersed solid phases.

Preparation of nano-particles of $\mathrm{UO}_{2}, \mathrm{ThO}_{2}$ and $(\mathrm{Th}, \mathrm{U}) \mathrm{O}_{2}$ by photochemical method using mercury UV lamps as the radiation source has been reported recently [8]. Solid precursors formed under the irradiation were subsequently heat treated at $300-550{ }^{\circ} \mathrm{C}$ to convert them to nano-crystalline oxides. Photochemical methods produce nano-sized powder with high specific surface area. Such kind of materials can be usually sintered at lower temperature [9-11] when compared to materials with larger particle size. The method produces solid precursors that are nitrogen and carbon free, thus allowing direct heat treatment in reducing atmosphere without pre-treatment in air.

This paper is focused on the pelletizing of photochemically prepared $\mathrm{UO}_{2}, \mathrm{ThO}_{2}$ and (Th, $\left.\mathrm{U}\right) \mathrm{O}_{2}$ nano-powders. Characterization and properties of the nano-powders, green pellets and sintered pellets, are discussed in detail. 


\section{Experimental}

Nano-crystalline $\mathrm{UO}_{2} / \mathrm{ThO}_{2}$ powders were prepared following the previously described procedure [8]. All solutions contained $0.1 \mathrm{~mol} \cdot \mathrm{dm}^{-3}$ ammonium formate $(\geq 99.995 \%$ trace metals basis, Sigma Aldrich). They consisted of either $0.01 \mathrm{~mol} \cdot \mathrm{dm}^{-3}$ uranyl nitrate (GR, Lachema Chemapol) or $0.01 \mathrm{~mol} \cdot \mathrm{dm}^{-3}$ thorium nitrate (p.a., Merck) or both $0.005 \mathrm{~mol} \cdot \mathrm{dm}^{-3}$ uranyl nitrate and $0.005 \mathrm{~mol} \cdot \mathrm{dm}^{-3}$ thorium nitrate. Solutions were prepared without any further purification of the chemicals. Deionized water was used in all experiments.

The solutions were irradiated for 60-180 minutes by low pressure mercury lamps TUV $25 \mathrm{~W}$ 4P SE (Speziallampen GmbH).

The solid precursors formed under irradiation were separated from the solutions by filtration (Millipore HAWP $0.45 \mu \mathrm{m}$ ), washed and dried at room temperature and structurally characterized by analysed via extended X-ray absorption fine structure (EXAFS) spectroscopy.

EXAFS measurements of the thorium and uranium precursors, contained in $1.5 \mathrm{~mm}$ thick aluminum frames with Kapton windows, were performed at the Th and $\mathrm{U} \mathrm{L}_{3} \mathrm{X}$-ray absorption edges, respectively. The data were collected at the wiggler beam line I811 at MAX-lab, Lund University, which operated at $1.5 \mathrm{GeV}$ and a maximum current of $220 \mathrm{~mA}$. The synchrotron beam was monochromatized using a Si[111] double crystal monochromator, with higher order harmonics reduced by detuning the second monochromator crystal to reflect $80 \%$ of maximum intensity at the energy at the end of the EXAFS range scanned. Measurements were performed simultaneously in transmission and fluorescence mode using ion chambers with stationary gas mixtures of krypton and helium and a Passivated Implanted Planar Silicon (PIPS) detector, respectively. The spectrum of a $\mathrm{Zr}$ foil (defined as $17.998 \mathrm{keV}$ [12]) was recorded simultaneously in transmission mode as reference. Spectra were recorded as continuous scans and averaged for the data analysis for all samples.

The EXAFS calculations were performed using the EXAFSPAK program package [13], incorporating the FEFF code [14]. The energy scale of each X-ray absorption spectrum was calibrated by assigning the first inflection point of the $\mathrm{K}$ edge of metallic zirconium foil to $17998 \mathrm{eV}$. The pre-edge was subtracted by fitting with a linear function. The background was removed with a $4^{\text {th }}$ polynomial spline fit using a Victoreen function for data collected in the fluorescence mode. The EXAFS function was $k^{3}$-weighted to enhance the contribution at higher $k$-values. Theoretical EXAFS spectra were computed with the FEFF code for single scattering (SS) paths, as well as multiple scattering (MS) ones. The fitting procedure was performed in $k$ - 
space. During the fitting procedure, the energy shift, $\Delta E$, and the amplitude reduction factor, $S_{o}^{2}$, were allowed to vary, but kept the same for all the paths in one sample.

Elemental $(\mathrm{C}, \mathrm{H}, \mathrm{N})$ analysis of the precursors was performed using a PERKIN ELMER 2400 Series II CHNS/O Analyser.

Subsequently, solid precursors were heat treated at $300-550^{\circ} \mathrm{C}$ in ambient air or under $\mathrm{Ar}: \mathrm{H}_{2}$ (10:1) atmosphere. The yields of uranium and/or thorium oxides formed were determined as described elsewhere [8].

X-ray diffraction (XRD) was used to identify and characterize the solid powder oxides and pellets, using Rigaku MiniFlex 600 diffractometer with $\mathrm{Cu}-\mathrm{K}_{\alpha 1,2}$ radiation $\left(\lambda_{\mathrm{av}}=0.15418 \mathrm{~nm}\right)$ and a scintillation detector; the ICDD PDF-2 database was used for the identification of prepared crystalline materials [15]. Linear crystallite size $(l)$ was calculated using Scherrer equation: $l=\left(0.89^{*} \lambda\right) /\left(B^{*} \cos \theta\right)$, where $\lambda$ is the wavelength of used radiation $(0.15418 \mathrm{~nm}), B$ is FWHM of selected peak obtained at higher $\theta$ after subtraction of instrument broadening and $\theta$ is Bragg diffraction angle. The instrumental broadening was determined by measurement of SRM640d standard. Specific surface area (SSA) of the solid precursors was measured by selective adsorption of nitrogen from the mixture of hydrogen and nitrogen at the temperature of liquid nitrogen [16].

Powder $\mathrm{UO}_{2}$ and/or $\mathrm{ThO}_{2}$ nanoparticles were pressed into pellets without addition of any lubricant or additives to the oxide powder. The powders have been pressed by a manual laboratory press (BSL - 2, BRIO Hranice s. r. o.), using stearic acid as die-wall lubricant. The powders were compacted at the pressure of $500 \mathrm{MPa}$ for 30 min into a pellet of $10 \mathrm{~mm}$ in diameter and $1 \mathrm{~mm}$ in theoretical height (the real height varied according to TD reached).

The prepared green pellets without any further treatment were additionally characterized using porosimetry (immersion into chloroform) and scanning electron microscopy (SEM) using a JEOL JSM 5510LV instrument. SEM images were taken from the unpolished surface of the green pellet. The geometric densities of the pellets were obtained by weighing and by measuring the pellet diameter and height with a digital calliper. Based on literature survey [5] and preliminary experiments, these pellets were subsequently sintered at relatively low temperatures to $1300{ }^{\circ} \mathrm{C}$ (temperature ramp $2{ }^{\circ} \mathrm{C} \mathrm{min}^{-1}$ ) for 3 hours under $\mathrm{Ar}: \mathrm{H}_{2}$ (20:1) mixture $\left(\mathrm{UO}_{2}\right.$ and $\left.(\mathrm{U}, \mathrm{Th}) \mathrm{O}_{2}\right)$ or $1600{ }^{\circ} \mathrm{C}\left(\operatorname{ramp} 2{ }^{\circ} \mathrm{C} \mathrm{min}^{-1}\right)$ for 6 hours in ambient air $\left(\mathrm{ThO}_{2}\right)$. Sintered pellets were consequently characterized in the exactly same manner as described for green pellets. 


\section{Results and discussion}

The EXAFS spectra of all thorium precursor samples were very similar to crystalline $\mathrm{ThO}_{2}$ standard, but the amplitudes are much smaller, Fig. 1. The refinement of structure parameters of all samples resulted in distances very close to those observed for crystalline $\mathrm{ThO}_{2}$, but the Debye-Waller factor coefficients, $\sigma^{2}$, were much larger. This strongly indicates that the samples have low degree of structural order, but in principle the same structures as crystalline $\mathrm{ThO}_{2}$. It should be emphasized that $\mathrm{ThO}_{2}$ was formed directly during irradiation of solutions, also in the presence of $\mathrm{U}$ in the solid precursor. According to XRD, the solid precursors are amorphous.

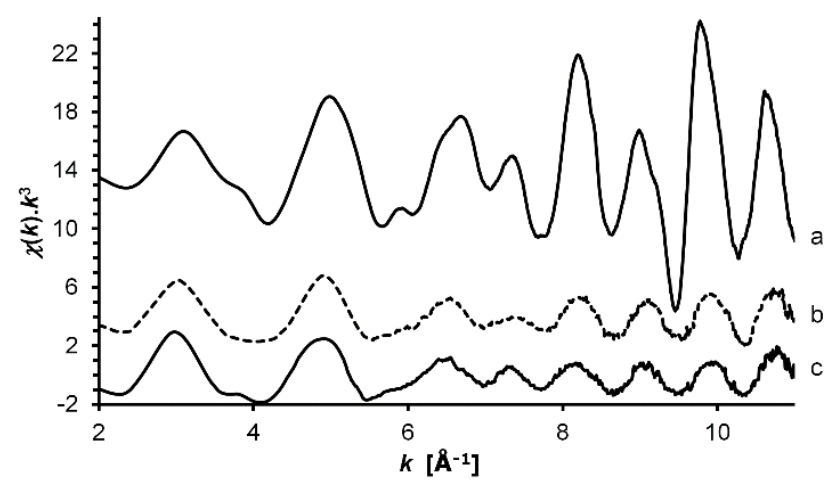

Fig. 1 EXAFS spectra of: a: solid $\mathrm{ThO}_{2}$ (offset: 14) and samples b: Th-containing precursor (offset: 4), and c: $\mathrm{Th}+\mathrm{U}$-containing precursor (no offset).

The EXAFS spectra of the uranium precursor samples show clearly presence of an uranyl(VI) unit with a $\mathrm{U}=\mathrm{O}$ bond distance of approximately $1.80 \AA$, and with additional U-O bonds most likely perpendicular to the linear uranyl unit in the region $2.3-2.4 \AA$. The comparison of the observed and reported $\mathrm{U} \cdots \mathrm{U}$ distances in the crystal structures did not lead to identification of the uranium compounds in the studied samples. The relatively large Debye-Waller factor coefficients indicate that the samples in this study have low structural order. The temperature of the complete conversion of solid precursor to oxide, atmosphere of heat treatment, oxide yields, linear size of the crystallites and SSA are summarized in Table 1:

Table 1 Conditions of oxides formation from amorphous precursors and formed oxides characteristics

\begin{tabular}{|c|c|c|c|c|c|}
\hline $\begin{array}{c}\text { Precursor for } \\
\text { oxide }\end{array}$ & \multirow{2}{*}{ Atmosphere } & $\begin{array}{c}\text { Temperature } \\
\text { of oxide } \\
\text { formation }\end{array}$ & Yield & $\begin{array}{c}\text { Linear } \\
\text { crystallite } \\
\text { size }[\mathrm{nm}]\end{array}$ & $\begin{array}{c}\text { SSA } \\
{\left[\mathrm{m}^{2} \cdot \mathrm{g}^{-1}\right]}\end{array}$ \\
\hline
\end{tabular}




\begin{tabular}{|c|c|c|c|c|c|}
\hline $\mathrm{UO}_{2}$ & Ar: $\mathrm{H}_{2}(10: 1)$ & $550{ }^{\circ} \mathrm{C}$ & $75 \%$ & 13.6 & 10.1 \\
\hline $\mathrm{ThO}_{2}$ & ambient air & $450{ }^{\circ} \mathrm{C}$ & $95 \%$ & 4.6 & 7.8 \\
\hline$(\mathrm{Th}, \mathrm{U}) \mathrm{O}_{2}$ & Ar: $\mathrm{H}_{2}(10: 1)$ & $300^{\circ} \mathrm{C}$ & $75 \%$ & 4.1 & 5.9 \\
\hline
\end{tabular}

The $\mathrm{UO}_{2}$ and/or $\mathrm{ThO}_{2}$ powders (prepared from precursors heat treated at minimal temperature sufficient for oxides formation - as summarized in Table 1) were compacted into pellets using stearic acid as a die-wall lubricant, characterized and then sintered. Characteristics of pellets are summarized in Table 2:

Table 2 Characteristics of green and sintered pellets

\begin{tabular}{|c|c|c|c|c|}
\hline Oxide & $\%$ TD (green) & $\%$ TD (sintered) & $\begin{array}{c}\text { Linear } \\
\text { crystallite size } \\
{[\mathrm{nm}]}\end{array}$ & $\begin{array}{c}\text { Lattice } \\
\text { parameter } \\
{[\mathrm{nm}]}\end{array}$ \\
\hline $\mathrm{UO}_{2}$ & 53.3 & 95.1 & 36.8 & 0.5474 \\
\hline $\mathrm{ThO}_{2}$ & 53.8 & 91.5 & 41.1 & 0.5598 \\
\hline$(\mathrm{Th}, \mathrm{U}) \mathrm{O}_{2}$ & 37.5 & 97.2 & 15.2 & 0.5513 \\
\hline
\end{tabular}

The densities of green pellets reached values from 37 to $54 \%$ TD. After the sintering, the pellets of $\mathrm{UO}_{2}$ and $(\mathrm{Th}, \mathrm{U}) \mathrm{O}_{2}$ reached the values exceeding $95 \% \mathrm{TD}$, whereas $\mathrm{ThO}_{2}$ pellets reached values exceeding $91 \%$ TD. The densities calculated from pellets dimensions are in good correlation with porosimetry measurements. Due to the nano-sized charasteristics of the powders used, even this low sintering temperature led to the pellets with high TD.

Photos of sintered pellets are shown in Fig. 2.

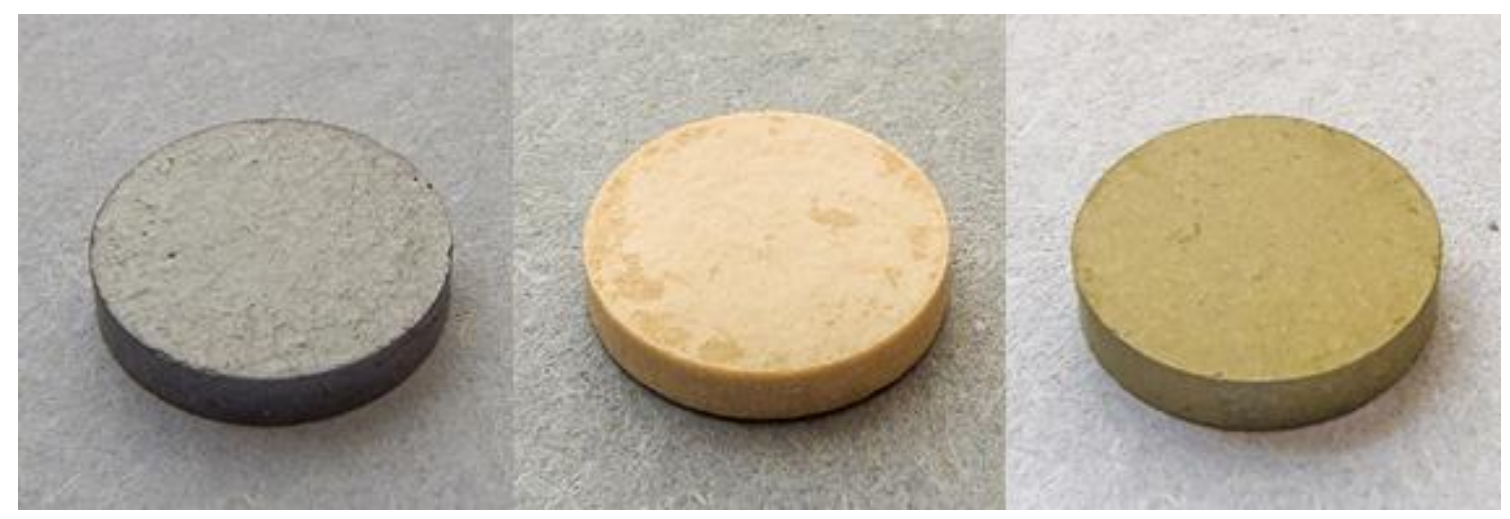

Fig. 2 Photos of sintered pellets; pellets are approximately of $8.5 \mathrm{~mm}$ in diameter and of 1.5 $\mathrm{mm}$ in height. Left: $\mathrm{UO}_{2}$ sintered at $1300{ }^{\circ} \mathrm{C}$; middle: $\mathrm{ThO}_{2}$ sintered at $1600{ }^{\circ} \mathrm{C}$ and right: $(\mathrm{Th}, \mathrm{U}) \mathrm{O}_{2}$ sintered at $1300{ }^{\circ} \mathrm{C}$. 
Both the XRD spectra of oxide powders and sintered pellets are shown in Figs. 3-5. Substantial improvement of crystallinity is observed, as the diffraction peaks FWHM (full-width at halfmaximum) were reduced by sintering. Slight shift of the maxima in the case of $\mathrm{UO}_{2}$ powders is caused by formation of oxide with slight excess of oxygen as described elsewhere [8]. A continuous transition from $\mathrm{U}_{4} \mathrm{O}_{9}$ to $\mathrm{UO}_{2}$ can be observed with increasing temperature of heat treatment. Lattice parameters of sintered oxides are summarized in Table 2. This also confirmed that the relatively low sintering temperature is sufficient for reducing the oxygen/metal ratio in the case of $\mathrm{UO}_{2}$ during the sintering.

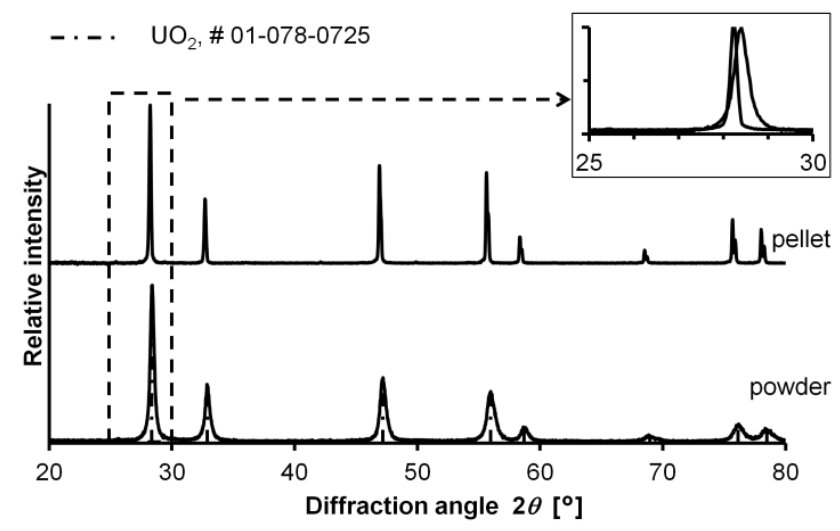

Fig. 3 XRD spectra of $\mathrm{UO}_{2}$ powder and XRD spectra of sintered pellet. XRD spectra of pellet were corrected on sample displacement $-0.344 \pm 0.016 \mathrm{~mm}$ at $R$ (goniometer radius) $=150 \mathrm{~mm}$. Diffraction lines of $\mathrm{UO}_{2}$ standard (ICDD PDF-2 database v. 2.02, record 01-078-0725) are inserted in the spectra.

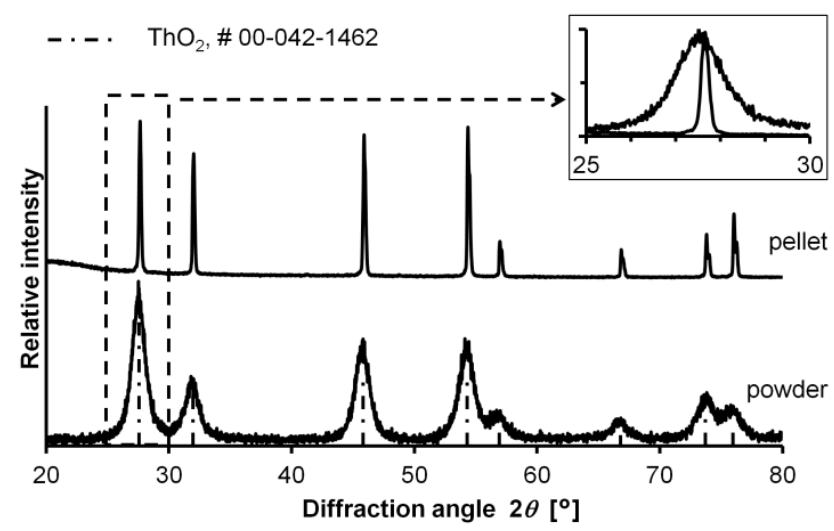

Fig. 4 XRD spectra of $\mathrm{ThO}_{2}$ powder and XRD spectra of sintered pellet. XRD spectra of pellet were corrected on sample displacement $-0.106 \pm 0.036 \mathrm{~mm}$ at $R=150 \mathrm{~mm}$. Slight increase of background at low diffraction angles is caused by a tape holding the pellet in the sample holder. Diffraction lines of $\mathrm{ThO}_{2}$ standard (ICDD PDF-2 database v. 2.02, record 00-042-1462) are inserted in the spectra. 


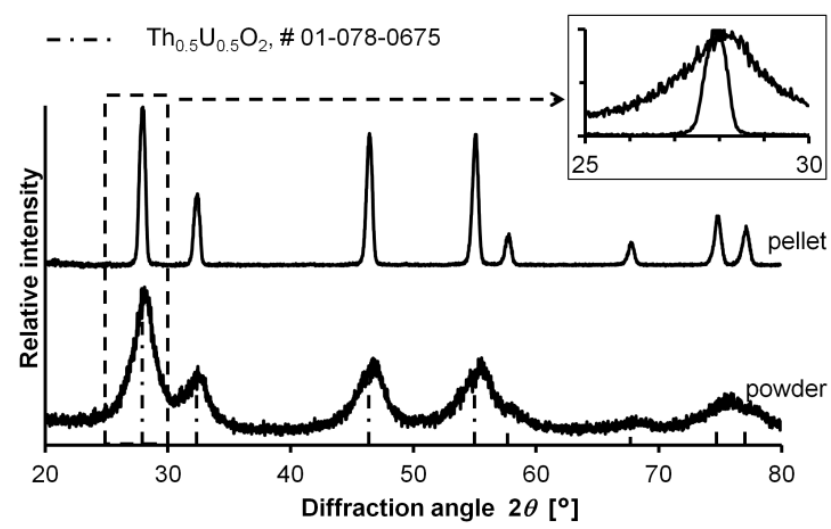

Fig. 5 XRD spectra of $(\mathrm{Th}, \mathrm{U}) \mathrm{O}_{2}$ powder and XRD spectra of sintered pellet. XRD spectra of pellet were corrected on sample displacement $0.217 \pm 0.012 \mathrm{~mm}$ at $R=150 \mathrm{~mm}$.

Diffraction lines of (Th,U)O 2 standard (ICDD PDF-2 database v. 2.02, record 01-078-0675) are inserted in the spectra.

SEM images of green and sintered pellets are shown in Fig. 6. The SEM pictures were taken from the surface of the pellets without any polishing or treatment. As it can be seen on the SEM images, sintering of the pellets resulted in the significant increase in particle size.

SEM images of the sintered pellets surface seem to confirm their low level of porosity; however, a few submicronic pores can be observed, dispersed throughout the pellet surface, located at grain boundaries. In some cases (see Fig. 6d), larger grains are surrounded by smaller ones, which occurs within the grain growth. Fig. 6e shows an example of homogeneous microstructure composed of submicron-sized aggregates bounded in a large network. Fig. $6 \mathrm{f}$ shows the significant increase in particle size due to the higher sintering tempterature (1600 ${ }^{\circ} \mathrm{C}$ ). In all pellets, grain growth was confirmed during sintering in comparison to initial precursor microstructure. Although the SEM images were taken from the unpolished surface of the pellets, images confirmed, that the last stage of sintering has been reached which is also consistent with the sintered density value. 


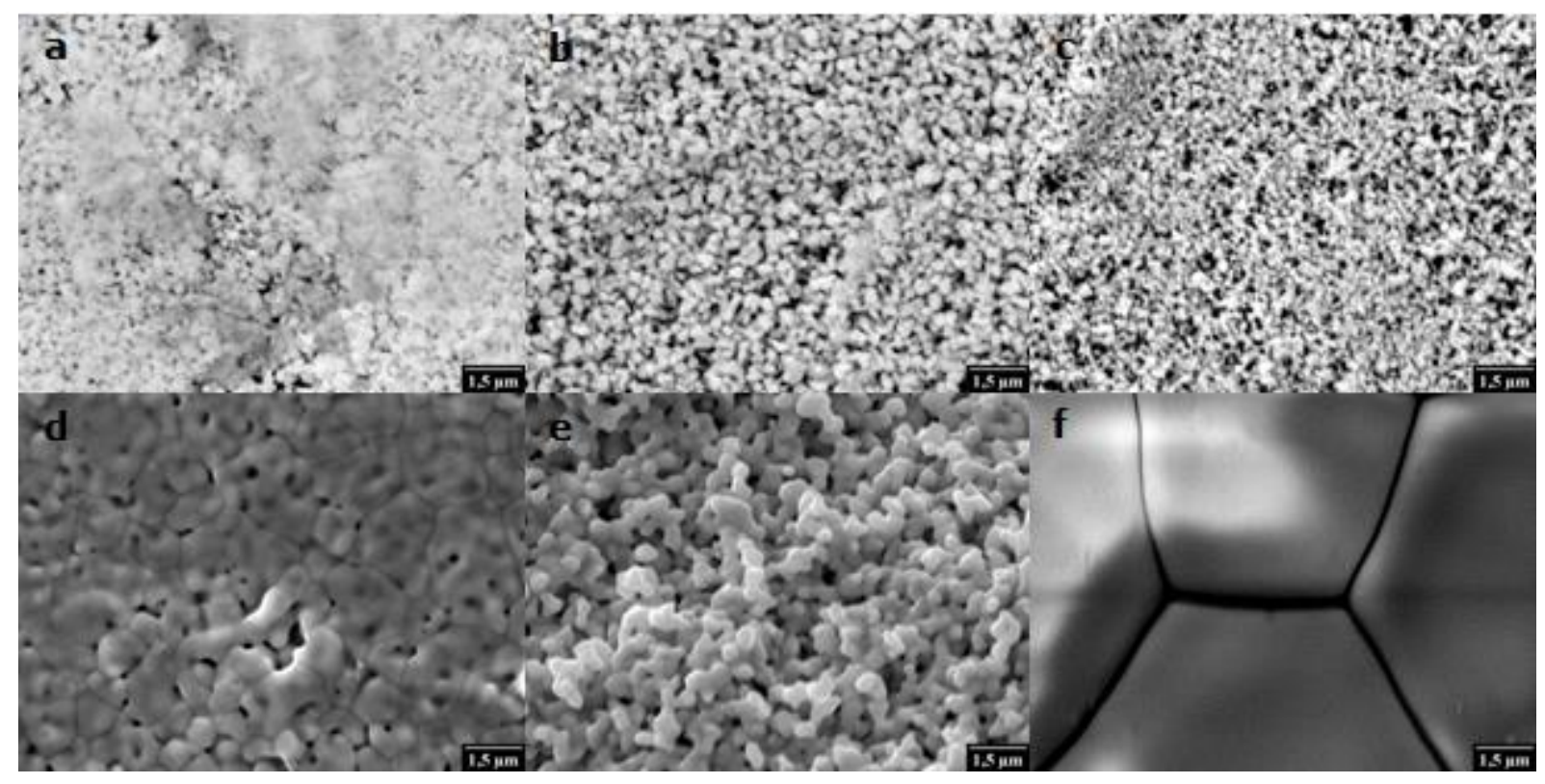

Fig. 6 SEM images of unpolished surface of green (on top, i.e. a-c) and sintered pellets (below, i.e. d-f) in back-scattered electrons $(\mathbf{a}, \mathbf{b}, \mathbf{c}, \mathbf{f})$ or secondary electron mode $(\mathbf{d}, \mathbf{e})$. Left: $\mathrm{UO}_{2}(\mathbf{a}$, d), middle: $(\mathrm{Th}, \mathrm{U}) \mathrm{O}_{2}(\mathbf{b}, \mathbf{e})$ and right: $\mathrm{ThO}_{2}(\mathbf{c}, \mathbf{f})$.

The scales in the down right corner of every image represent the scale of $1.5 \mu \mathrm{m}$.

\section{Conclusions}

Pelletizing of photochemically prepared nano-powders of erystalline $\mathrm{UO}_{2}, \mathrm{ThO}_{2}$ and (Th, $\left.\mathrm{U}\right) \mathrm{O}_{2}$ have been studied. The obtained nano-powders are carbon free, allowing direct heat treatment in reducing atmosphere without pre-treatment in air. The EXAFS analyses of the precursors indicate that the Th-containing precursors are $\mathrm{ThO}_{2}$ (direct formation of $\mathrm{ThO}_{2}$ ), whereas the $\mathrm{U}$ containing precursors are the mixture of uranium(IV) and uranium(VI) compounds.

The $\mathrm{UO}_{2}$ and/or $\mathrm{ThO}_{2}$ powders were compacted into pellets using stearic acid as a die-wall lubricant and then sintered at temperature of $1300{ }^{\circ} \mathrm{C}$ under $\mathrm{Ar}: \mathrm{H}_{2}(10: 1)\left(\mathrm{UO}_{2}\right.$ and (Th, $\mathrm{U}_{2} \mathrm{O}_{2}$ pellets) and at temperatures up to $1600{ }^{\circ} \mathrm{C}$ in ambient air ( $\mathrm{ThO}_{2}$ pellets). No binder was used during the pelletizing and comparatively low sintering temperature was sufficient for $\mathrm{UO}_{2}$ (and $(\mathrm{Th}, \mathrm{U}) \mathrm{O}_{2}$ ) pellets preparation. The densities of green pellets reached values from 37 to $54 \%$ TD, sintered pellets reached values from $91 \%$ to $97 \%$ TD.

The prepared green pellets are highly durable as only one pellet was typically sufficient for characterization and sintering procedures without substantial damage to the pellets. Based on the obtained results, the photochemical method offers promising alternative route for preparation of both single and mixed oxide fuel pellets. 


\section{Acknowledgements}

This work has been supported by the European FP7 ASGARD (EC-GA No. 295825) and TALISMAN (TALI-C03-08) project, under contract with the European Commission and by the Grant Agency of the Czech Technical University in Prague project SGS14/207/OHK4/3T/14. Authors would like to thank to Mr. Jan Adámek for SEM images and Ms. Stanislava Matějková for elemental analysis. "Portions of this research were carried out at beam-line I811, MAX-lab synchrotron radiation source, Lund University, Sweden. Funding for the beam-line I811 project was kindly provided by The Swedish Research Council and the "Knut och Alice Wallenbergs Stiftelse."

\section{References}

[1] M. Keskar, U.M. Kasar, K. Krishnan, N.D. Dahale, S.K. Sali, S. Kannan, J. Nucl. Mater. 452 (2014) 24-30.

[2] T. Arima, K. Yoshida, T. Matsumoto, Y. Inagaki, K. Idemitsu, J. Nucl. Mater. 445 (2014) 175-180.

[3] T. Abe, K. Asakura, 2.15 Uranium Oxide and MOX Production, in: R. Konings, T. Allen, R. Stoller, S. Yamanaka (Eds.), Comprehensive Nuclear Materials. Elsevier, Amsterdam, 2012, 394-422.

[4] P.R. Hania, F.C. Klaassen, 3.04 Thorium Oxide Fuel, in: R. Konings, T. Allen, R. Stoller, S. Yamanaka (Eds.), Comprehensive Nuclear Materials. Elsevier, Amsterdam, 2012, 88108.

[5] S. Anthonysamy, K. Ananthasivan, V. Chandramouli, I. Kaliappan, P.R. Vasudeva Rao, J. Nucl. Mater. 278 (2000) 346-357.

[6] Z. Chen, G. Subhash, J.S. Tulenko, J. Nucl. Mater. 454 (2014) 427-433.

[7] V. Čuba, T. Pavelková, J. Bárta, T. Gbur, M. Vlk, A. Zavadilová, J. Indrei, Z. Dočekalová, M. Pospíšil., V. Múčka, Radiat. Phys. Chem. 81 (2012) 1411-1416.

[8] T. Pavelková, V. Čuba, F. Šebesta, J. Nucl. Mater. 442 (2013) 29-32.

[9] P. Bowen, C. Carry, Powder Technol. 128 (2002) 248-255.

[10] R. Chaim, M. Levin, A. Shlayer, C. Estournes, Adv. Appl. Ceram. 107 (2008) 159-169.

[11] A. Bel, R. Delmas, B. Francois, J. Nucl. Mater. 1 (1959) 259-270.

[12] A. Thompson, D. Attwood, E. Gullikson, M. Howells, K.J. Kim, J. Kirz, J. Kortright, I. Lindau, Y. Liu, P. Pianetta, A. Robinson, J. Scofield, J. Underwood, G. Williams, H. Winick, X-ray Data Booklet, Lawrence Berkley National Laboratory, 2009. 
[13] G.N. George, I.F. Pickering, EXAFSPAK - A suite of Computer Programs for Analysis of X-ray absorption spectra, Stanford Synchrotron Radiation Laboratory, Stanford, CA, 1995. (accessed May 2015) http://www-ssrl.slac.stanford.edu/exafspak.html

[14] S.I. Zabinsky, J.J. Rehr, A. Ankudinov, R.C. Albers, M. Eller, Phys. Rev. B, 1995 (52) 2995-3009.

[15] ICDD PDF-2 database, release 2013, database version 2.1302, sets 00-01-63 + 01-70-89 + 04-65-66 + 05-01. DDView program, version 4.13.3.6 (2013). JCPDS-ICDD International Centre for Diffraction Data, Newtown Square, USA.

[16] F.M. Nelsen, F.T. Eggertsen, Anal. Chem. 30 (1958) 1387-1390. 